IZA DP No. 9887

High Times: The Effect of Medical Marijuana Laws on Student Time Use

Yu-Wei Luke Chu

Seth Gershenson

April 2016 


\title{
High Times: The Effect of Medical Marijuana Laws on Student Time Use
}

\author{
Yu-Wei Luke Chu \\ Victoria University of Wellington \\ Seth Gershenson \\ American University \\ and IZA
}
Discussion Paper No. 9887
April 2016

\author{
IZA \\ P.O. Box 7240 \\ 53072 Bonn \\ Germany \\ Phone: +49-228-3894-0 \\ Fax: +49-228-3894-180 \\ E-mail: iza@iza.org
}

\begin{abstract}
Any opinions expressed here are those of the author(s) and not those of IZA. Research published in this series may include views on policy, but the institute itself takes no institutional policy positions. The IZA research network is committed to the IZA Guiding Principles of Research Integrity.

The Institute for the Study of Labor (IZA) in Bonn is a local and virtual international research center and a place of communication between science, politics and business. IZA is an independent nonprofit organization supported by Deutsche Post Foundation. The center is associated with the University of Bonn and offers a stimulating research environment through its international network, workshops and conferences, data service, project support, research visits and doctoral program. IZA engages in (i) original and internationally competitive research in all fields of labor economics, (ii) development of policy concepts, and (iii) dissemination of research results and concepts to the interested public.
\end{abstract}

IZA Discussion Papers often represent preliminary work and are circulated to encourage discussion. Citation of such a paper should account for its provisional character. A revised version may be available directly from the author. 


\section{ABSTRACT \\ High Times: \\ The Effect of Medical Marijuana Laws on Student Time Use ${ }^{*}$}

Twenty-three states and the District of Columbia have passed medical marijuana laws. Previous research shows that these laws increase marijuana use among adults. In this paper, we estimate the effects of medical marijuana laws (MML) on secondary and postsecondary students' time use using time diaries from the American Time Use Survey. We apply a difference-in-differences research design and estimate flexible fixed effects models that condition on state fixed effects and state-specific time trends. We find that on average, part-time college students in MML states spend 42 fewer minutes on homework, 37 fewer minutes attending class, and 60 more minutes watching television than their counterparts in non-MML states. However, we find no effects of MMLs on secondary or full-time college students. These results provide evidence on the mechanisms through which marijuana use affects educational outcomes, young peoples' behavioral responses to MMLs (and reduced costs of obtaining marijuana), and that the impact of MMLs on student outcomes are heterogeneous and stronger among disadvantaged students.

JEL Classification: $\quad$ I18, K32, K42

Keywords: $\quad$ time use, medical marijuana, unintended consequences

Corresponding author:

Seth Gershenson

School of Public Affairs

American University

4400 Massachusetts Avenue, NW

Washington DC, 20016-8070

USA

E-mail: gershens@american.edu

\footnotetext{
* The authors thank Stephen B. Holt for providing excellent research assistance. Any remaining errors are our own.
} 
"I now have absolute proof that smoking even one marijuana cigarette is equal in brain damage to being on Bikini Island during an H-bomb blast."

- Ronald Reagan, 40th U.S. President.

\section{Introduction}

It is a popular belief that marijuana use causes poor educational performance, such as school dropout and truancy. Not only is there a strong correlation between marijuana use and low educational attainment, but medical research suggests that marijuana can affect motivation, attention, and cognitive abilities. However, empirical evidence on the causal link between marijuana use and educational outcomes is rather limited outside the laboratory. Despite significant policy implications, there are relatively few economic studies on the topic. Moreover, much of the extant literature relies on strong identification assumptions, and it is unclear to what extent the findings in prior research are driven by unobserved heterogeneity. A key difficulty in identifying the causal effect of marijuana use on educational outcomes is identifying arguably exogenous variation in marijuana consumption.

Over the past two decades, more than twenty U.S. states have passed medical marijuana laws (MMLs) that effectively allow patients to legally possess and use marijuana. Such laws are naturally controversial, as they have the potential to increase illicit marijuana use among non-patients. Large surveys such as the National Survey on Drug Use and Health (NSDUH) document a strong, positive correlation between MMLs and marijuana use (Wall et al. 2011; Cerdá et al. 2012). This correlation could be causal as MMLs lower non-patients' marginal cost of marijuana use through several channels. First, MMLs might increase non-patients' access to marijuana and lower the drug's real and/or shadow price (Salomonsen-Sautel et al. 2012; Thurstone, Lieberman, and Schmiege 2011; Anderson, Hansen, and Rees 2013). Second, MMLs could shift social attitudes toward marijuana use and decrease stigma or the perceived harm associated with its use (Khatapoush and Hallfors 2004). Finally, MMLs could cause law enforcement and the judicial system to take a more lenient approach to illegal marijuana use (GAO 2002; Eddy 2010). ${ }^{1}$

Several recent studies provide evidence of a causal relationship and show that MMLs cause a 10-20\% increase in marijuana use (Chu 2014, 2015; Wen, Hockenberry, and Cummings 2015). Somewhat surprisingly, the increase in marijuana use is concentrated among adults, as MMLs do not affect marijuana usage among juveniles (Wen, Hockenberry, and

\footnotetext{
${ }^{1}$ In fact, cities like Denver, San Francisco, and Seattle, passed initiatives that either legalize marijuana or require authorities to make marijuana offenses 'the lowest law enforcement priority' (Eddy 2010).
} 
Cummings 2015; Anderson, Hansen, and Rees 2015). A small but growing literature utilizes MMLs as a policy shock to study the effects of marijuana use on relevant health outcomes. For example, Anderson, Hansen, and Rees (2013) find that MMLs reduce alcohol consumption and traffic fatalities involving alcohol, suggesting that marijuana and alcohol are substitutes. Chu (2015) finds that marijuana is not a complement to cocaine and heroin, as the use of these drugs does not increase after the passage of MMLs. Powell, Pacula, and Jacobs (2015) show that medical marijuana states experience a relative decrease in opioid addictions and opioid overdose deaths. MMLs may affect behaviors as well, perhaps because marijuana use crowds out other activities or consumption. Anderson, Rees, and Sabia (2014) find that MMLs reduce suicide rates among younger men, and Sabia et al. (2015) find that MMLs reduce the prevalence of obesity.

The general finding that MMLs affect non-patients' marijuana use and health behaviors suggests that MMLs might affect educational attainment by changing students' behaviors. For example, the behavioral changes caused by MMLs documented in the previous literature might cause students to spend less time attending class and less time studying outside of class. We formally test these hypotheses, and, in doing so, provide novel evidence on the impact of MMLs on student behaviors both in and out of the classroom and contribute to our understanding of the causal relationship between marijuana use and behaviors associated with educational success. Specifically, we use time diary data from the nationally representative American Time Use Survey (ATUS) to estimate difference-in-differences time-use regressions that control for state fixed effects, state-specific time trends, and a variety of student and timediary covariates.

Consistent with extant evidence that MMLs do not affect juvenile drug use, we find no effect of MMLs on high-school students' time use. Effects on post-secondary students are negative, but appear to be heterogeneous and stronger among disadvantaged students. We find that MMLs only affect part-time college students, and the effects are particularly strong among traditionally underrepresented students. For example, among part-time college students, the decreases in homework and class time among black students are more than twice as large as those for white students. On an average day, after the passage of MMLs, part-time college students spend 42 fewer minutes doing homework and 37 fewer minutes attending class. Interestingly, these decreases were offset by increased time in an educationally unproductive activity: part-time college students' time spent watching television increased by about 60 minutes per day. When time is measured in terms of the proportion of non-sleep time, these effects are estimated to be around $4-5 \%$ of non-sleep time. Changes on the extensive margin 
contribute to the reduction in homework and in-class time, while the increase in television time occurs only on the intensive margin. Our findings suggest that marijuana use may harm educational outcomes among relatively disadvantaged students and are consistent with the results in Marie and Zölitz (2015), who find that university students' academic performance increased at Maastricht University after legal access to marijuana was removed, particularly that of relatively low-performing students. Moreover, our findings provide evidence on the mechanisms through which these effects may operate.

This research makes several contributions. First, this paper leverages a new identification strategy — the exogenous shock of MMLs — for detecting the effects of marijuana use on intermediate educational outcomes. Previous studies either use instrumental variables that are largely based on cross-sectional variation, or try to model individual heterogeneity econometrically, with Marie and Zölitz (2015) being a notable exception. In contrast, the current study exploits a more plausible source of exogenous variation in marijuana consumption. Second, students' behavioral responses to MMLs are of policy interest in their own right. The finding of stronger negative effects on the educationally productive activities of underrepresented, potentially disadvantaged groups is particularly relevant to discussions of inequality and the design of future education and health policies. Finally, while MMLs provide numerous benefits to the patients, unintended negative externalities associated with increased access to marijuana exist. Identifying and quantifying unintended consequences of public policy is paramount to conducting careful cost-benefit analyses and to improving future iterations of policies.

The paper proceeds as follows: Section 2 briefly describes the history of MMLs and what is known about the relationship between marijuana use and educational outcomes. Sections 3 and 4 describe the data and empirical strategy, respectively. Section 5 presents the results and section 6 concludes.

\section{Background and Literature Review}

\subsection{History of Medical Marijuana Laws}

In the late 1970s, many states began passing legislation that allowed the use of medical marijuana through research programs, but only a handful of states' research programs became operable due to strict federal restrictions (Pacula et al. 2002). In 1986, the Food and Drug Administration (FDA) approved Marinol, a prescription drug containing the same active ingredient, Delta-9-THC, as marijuana. However, taking oral medications could be difficult for patients suffering from severe nausea, a common symptom among AIDS and cancer patients. 
In the late 1980 s and early 1990s, smokable marijuana was discovered to benefit growing populations of AIDS and cancer patients. In 1996, California became the first state to pass a medical marijuana law allowing patients to legally use and possess marijuana. With growing positive medical evidence and lobbying by marijuana legalization advocacy groups, such as the National Organization for the Reform of Marijuana Laws (NORML), many states have since joined California in passing a new wave of medical marijuana legislation. As of 2014, 23 states and the District of Columbia have passed similar medical marijuana laws. States with effective medical marijuana laws, and the years they passed, are summarized in Table 1.

These laws permit patients with legally designated diseases and syndromes to use marijuana as a means of treatment. The designated symptoms and conditions typically include AIDS, anorexia, arthritis, cachexia, cancer, chronic pain, glaucoma, migraines, persistent muscle spasms, severe nausea, seizures, and sclerosis. Patients can legally possess marijuana up to a fixed amount that varies by state. Since these medical marijuana laws do not change the criminal status of marijuana, only legal patients can be exempted from state penalties. To become a legal patient, individuals need a recommendation from a physician. ${ }^{2}$ In most states, legal patients also need to register with the state medical marijuana program and obtain a medical marijuana card. ${ }^{3}$ The number of registered patients was quite small before 2009, but has increased dramatically in recent years. For example, Colorado passed its medical marijuana law in 2001 and had only 5,051 registered patients in January 2009. By January 2010, however, the number of registered patients had increased more than 2,000 percent in just one year to 118,895. An estimate from ProCon.org (2016) suggests that there are about 1.2 million legal patients in 2016 , or about $0.8 \%$ of the total population of medical marijuana states.

Medical marijuana laws passed prior to the Obama administration generally do not authorize marijuana dispensaries in order to conform to federal classification of marijuana as a Schedule I drug. To overcome the supply issue, these laws allow for home cultivation. Patients can grow for their own and for other patients' use on a not-for-profit basis. Marijuana dispensaries with grey legal status still exist, however. The prevalence of dispensaries largely depends on the attitude of local governments and the actions of local law enforcement, which could change from time to time. In 2007, New Mexico became the first state to pass a medical marijuana law with a provision to license production and distribution at the state level, but the

\footnotetext{
${ }^{2}$ Federal law does not allow physicians to 'prescribe' marijuana.

${ }^{3}$ California created a registration program in 2004, but registration is voluntary. Maine passed an amendment in November 2009 that created a registration program, but it remains voluntary. Washington does not have a registration program. Notice that, in some states, such as Colorado and Nevada, patients who do not join the registry and are arrested for marijuana charges may argue an "affirmative defense of medical necessity."
} 
first state-licensed marijuana provider in New Mexico was not approved until March 2009. ${ }^{4}$ In 2009, the Obama administration announced that the federal government would no longer seek to arrest medical marijuana users and suppliers so long as they conformed to state laws (Mikos 2011). This statement largely resolved the legal dispute between state and federal governments. As a result, laws and amendments now regulate dispensaries, and both the numbers of registered patients and dispensaries have increased significantly since then.

\subsection{Marijuana Use and Educational Outcomes}

Strong correlations between marijuana use and educational outcomes such as school dropout and truancy are well documented (e.g., Lynskey and Hall 2000; Macleod et al. 2004). On the one hand, such associations may be causal, owing to changes in motivation, cognitive ability, and other psychological effects of marijuana use. Numerous laboratory experiments find that marijuana users exhibit lower motivation and cognitive impairment (Foltin et al. 1989; Musty and Kaback 1995; Lane et al. 2005; Griffith-Lendering et al. 2012; Shannon et al. 2010; Randolph et al. 2013; Wetherell et al. 2012; Bolla et al. 2005; Verdejo-Garcia et al. 2007; Whitlow et al. 2004). Heavy marijuana use is also associated with depression (Degenhardt, Hall, and Lynskey 2003). Moreover, many recent studies utilize magnetic resonance imaging (MRI) to show brain abnormalities among marijuana users (Price et al. 2015; Wesley, Hanlon, and Porrino 2011; Batalla et al. 2014; Vaidya et al. 2012; Gilman et al. 2014; Raver, Haughwout, and Keller 2013; Filbey et al. 2014; Bolla et al. 2005). Some evidence suggests that the impacts of marijuana use on the brain could be permanent, and brain abnormities can be found even among casual and abstinent users (Raver, Haughwout, and Keller 2013; Bolla et al. 2005; Gilman et al. 2014).

On the other hand, the correlation might be spurious and driven by individual heterogeneity. Most of the laboratory experiments mentioned above are not randomized control experiments. Due to ethical issues, researchers cannot randomly assign marijuana use to experiment subjects, and instead recruit volunteer marijuana users as experiment subjects. It is unclear to what extent the psychological effects found in the medical literature are indeed causal. For example, Denson and Earleywine (2006) suggest that some marijuana use may be self-medication, and marijuana users generally have less depressed moods than nonusers. Weiland et al. (2015) point out that in many previous studies marijuana users are observably

\footnotetext{
${ }^{4}$ Dispensaries are considered to be legally protected in California (Senate Bill 420, 2003) and Colorado; their laws do recognize the existence of dispensaries even though they are silent as to their legality (Pacula, Boustead, and Hunt 2014; Pacula et al. 2015).
} 
different from nonusers in terms of alcohol use and along several other dimensions, and the researchers find no association between marijuana use and standard MRI brain shape measurements after carefully controlling for alcohol use, gender, age, and other variables. Filbey et al. (2014) also point out that current MRI evidence is largely correlational, and longitudinal studies that can trace changes over time are needed to determine causality. In addition, peer behaviors appear to affect marijuana use (Gaviria and Raphael 2001; Duarte, Escario, and Molina 2009). Thus, poor academic performance among marijuana users could be a result of social interaction and self-selection into low-achieving peer groups. A final concern in this literature is reverse causality, as Sander (1998) and Zimmerman and Schmeelk-Cone (2003) suggest that school performance may affect marijuana initiation and usage.

Perhaps due to a general lack of plausible exogenous variation, only a handful of studies have attempted to determine the causal association between marijuana use and educational attainment. Most research uses instrumental variables and simultaneous equation models to address endogeneity problems (Chatterji 2006; Roebuck, French, and Dennis 2004; Yamada, Kendix, and Yamada 1996; Bray et al. 2000; Duarte, Escario, and Molina 2006). For example, state beer taxes, marijuana and cocaine prices, marijuana penalties, and de-penalization status have been used as instruments for marijuana use. Some research also relies on econometric modelling to control for individual heterogeneity (van Ours and Williams 2009; Duarte, Escario, and Molina 2006; Roebuck, French, and Dennis 2004). The literature finds evidence of a negative causal link between marijuana use and education attainment. However, these conclusions should be treated with caution, as the identification in these studies tends to rely on strong assumptions. For example, the instruments are generally weak and arguably endogenous. McCaffrey et al. (2010) shows that estimates are sensitive to different control variables and propensity score weights, suggesting that unobserved heterogeneity remains an important factor. Moreover, medical research utilizing data on twins finds no causal effects of marijuana use on educational attainment (Grant et al. 2012; Bergen et al. 2008; Verweij et al. 2013). A recent exception to this critique is Marie and Zölitz (2015), who use a difference-indifferences strategy to estimate the effect of a policy that removed college students' legal access to marijuana. The authors find that student performance at Maastricht University increased after legal access was removed, that this effect was driven by younger university students, and provide suggestive evidence that these improvements were due to increased understanding of material rather than changes in students' effort provision.

We contribute to this literature by investigating the channels through which access to marijuana might affect educational achievement and attainment. Specifically, we provide 
reduced-form evidence on the causal effect of MMLs on student behaviours associated with educational success. Intuitively, MMLs might increase marijuana use among secondary and post-secondary students by reducing the costs associated with procuring and using marijuana. We therefore estimate MMLs' effects on time spent studying and watching television, both which might influence educational achievement and attainment (Jacob 2002; Kalenkoski \& Pabilonia 2014), as studying is an input in the education production function and television viewing crowds out other more educationally productive activities.

\section{Data}

The current study examines the effect of medical marijuana laws on secondary and postsecondary students' time use, which captures behavioral responses to the laws that are of interest in their own right, but also a potential mechanism through which medical marijuana laws might affect educational achievement and attainment. Prevailing social attitudes towards how individuals spend their time likely influence responses to traditional survey questions, a phenomenon known as social desirability bias (Grimm 2010). Accordingly, retrospective time diaries likely yield more accurate measures of students' non-school time use (Juster \& Stafford 1991). We therefore analyze time diaries collected by the American Time Use Survey (ATUS).

The ATUS is a nationally representative survey that has been administered annually since 2003 by the Bureau of Labor Statistics. The ATUS collects a 24-hour retrospective time diary from one individual aged 15 or over per household from a subset of the Current Population Survey (CPS) sampling frame and links each diary to socio-demographic household data from the CPS. The analytic sample of almost 15,000 time diaries is restricted to respondents who self-reported being enrolled in high school or college at the time of completing the time diary, for whom basic demographic variables are observed. ${ }^{5}$ Because weekends and certain demographic groups and months are oversampled by the ATUS, all subsequent analyses are weighted by person-day weights that account for unequal probabilities of selection across households, months, and days of the week. The person-day nature of the sampling weights reinforces the fact that time diary surveys sample both individuals and calendar days.

Table 2 summarizes the students who comprise the three analytic samples of the three populations of interest: high school students, full-time college students, and part-time college

\footnotetext{
5 We use diaries from the full calendar year, including summer months. However, as shown in Table 7, the main results are robust to using only diaries completed during the traditional academic year (September - May).
} 
students. The first set of statistics summarize students' participation in three activities, homework, classes, and television viewing, on both the intensive and extensive margins. First, on average, full-time college students perform about 1.5 hours of homework per day, which is about twice as much time spent by either high school or part-time college students. Daily average homework time is significantly larger for students who engage in at least some homework on the diary day for all three types of students, and this increase is reflected in the daily participation rates: only about 40 percent of high school and full-time college students, and 27 percent of part-time college students, performed any homework on the diary day. On both the intensive and extensive margins, full-time college students spend more time on homework than the other types of students. However, while high school students are more likely to participate in homework than part-time college students on a given day, conditional on participating in homework, part-time college students spend about 50 more minutes per day than high school students. This could be because part-time college students have more compartmentalized schedules, where some days are allocated to classes and coursework while other days are allocated to childcare or participation in the labor market. Second, high school students spend significantly more time in class, and are more likely to spend any time in class, than college students. Similarly, full-time college students spend more time in class, and are more likely to spend any time in class, than part-time college students. Intuitively, these differences are due to systematic differences in school schedules between types of students. Finally, television viewing habits are fairly similar across the three student groups. Television viewing is common among students, as 70 to 76 percent of students watch at least some television on any given day and when they did, they averaged more than two hours of television time.

The remainder of table 2 summarizes the demographic composition of the analytic samples. The sexes are evenly represented in high school, but females outnumber males in college. The latter is consistent with the emerging gender gaps in college enrollment and completion that favor females (Bailey \& Dynarski 2011). There is also an intuitive age gradient, as college students are older than high school students and part-time college students are older than full-time college students. Again, the latter is consistent with nationwide trends in college going, as are the subtle differences by race.

\section{Econometric Model}

We implement a difference-in-differences style identification strategy by estimating linear regressions of the form 


$$
\text { Time }_{i s t}=\tau M M L_{s t}+\beta X_{i s t}+\delta_{t}+\theta_{s}+\gamma t \theta_{s}+\varepsilon_{i s t},
$$

where Time is a measure (in minutes) of the time that respondent $i$ spent on a particular activity on the diary day; $M M L$ is a binary indicator equal to one if state $s$ had a medical marijuana law in effect in year $t$, and zero otherwise ${ }^{6} X$ is a vector of observed respondent, diary, and timevarying state characteristics; $\theta$ and $\delta$ are state and year fixed effects (FE), respectively; and $\varepsilon$ is an idiosyncratic error term. ${ }^{7}$ The parameter of interest is $\tau$, which represents the impact of state MMLs on average daily student time use. Standard errors are clustered by state, to make statistical inference robust to heteroskedasticity and serial correlation within states over time, as the treatment occurs at the state level.

The critical identifying assumption necessary to give OLS estimates from a differencein-difference research design a causal interpretation is the parallel trends (i.e., common slopes) assumption. Intuitively, this means that after controlling for level differences between states with the state FE, time use in both treated (MML) and control (non-MML) states was trending similarly. However, if unobserved secular trends jointly determined both time use and states' adoptions of MMLs, the OLS estimates from a fixed effects regression will be biased. Accordingly, we augment equation (1) in two ways to test and relax the parallel trends assumption. First, equation (1) conditions on state-specific linear time trends $\left[\gamma t \theta_{s}\right.$ in equation (1)]. This explicitly relaxes the parallel trends assumption by allowing each state, regardless of treatment status, to follow its own linear time trend (e.g., Wooldridge, 2010). The resulting estimator identifies state-specific departures from trend in response to the passage of MMLs. Second, we estimate an event-study version of equation (1) that includes binary indicators for policy leads and lags. Intuitively, this allows us to test for "effects" of MMLs before they were passed. Should such "effects" be observed, this is evidence of differential, pre-existing trends

\footnotetext{
${ }^{6}$ One potential concern with the binary MML indicator is that there is potential heterogeneity across state legislations (e.g., whether or not the state allows dispensaries) (Pacula et al. 2015). However, Chu (2015) and Wen, Hockenberry, and Cummings (2015) find little evidence that such differences are practically important. Moreover, it is difficult to distinguish differences in laws from regime/time effects, as most MMLs allowing for dispensaries were passed after 2008 and only a handful of states enacted any specific type of MML at a given time. Therefore, we maintain the conventional assumption of a homogenous treatment to maintain power and avoid bias in the standard errors due to a small number of treatment groups (Conley and Taber 2011).

${ }^{7}$ OLS estimates of linear time-use regressions are preferred despite the "pile-up" at zero inherent in daily time use data for two reasons. First, Stewart (2013) shows that OLS estimates are more robust than Tobit estimates when daily non-participation is caused by measurement error attributable to time diary surveys' sampling of days. Second, the linear model facilitates the inclusion of state fixed effects and state-specific linear time trends that aid in identification. Because MMLs are not uniformly enacted on January 1st and the ATUS records the specific date of the time diary, we adjust the MML indicator to equal one if and only if the MML was in effect at the time of respondent $i$ 's time diary. For example, an individual surveyed in January of year $t$ would not be considered treated if the MML was enacted in May of year $t$.
} 
in MML states. Together, the state time trend and event study sensitivity analysis will provide evidence of the credibility of our estimates of the causal effect of MMLs on students' time use.

\section{Results}

Table 3 presents baseline estimates of $\tau$, which represent MMLs' impacts on daily time use, from equation (1). We estimate the model separately for three types of students: high school students, full-time college students, and part-time college students. Each panel of table 3 reports the estimated impact of MMLs on daily minutes spent in one of three activities: studying and homework outside of school (upper panel), time in class or at school (middle panel), and television viewing (lower panel). For each student category, we present estimates from two specifications: First, we estimate a parsimonious specification that only includes indicators for marijuana legalization and decriminalization, state fixed effects, state-specific linear time trends, and controls for the date of the time diary (i.e., year, month, and day of week fixed effects). Second, we estimate an extended specification that also controls for students' socio-demographic backgrounds. Thus each cell of table 3 reports the estimated effect of MMLs from a unique regression.

Columns 1 and 2 of table 3 show that there is no significant effect of MMLs on high school students' time use, as the estimates are relatively small in magnitude and not statistically significant at traditional confidence levels. This is unsurprising, as the extant literature finds no evidence that MMLs affect high school students' marijuana use. However, the impact of MMLs on college students' time use varies by students' enrollment status. Specifically, columns 3 and 4 estimate the models for full-time college students while columns 5 and 6 do so for part-time college students. Like the case of high school students, the estimates in columns 3 and 4 provide no evidence of an effect of MMLs on full-time college students' time use. This might be because most full-time college students transition directly to college from high school and thus behave similarly (Radford, Cominole, \& Skomsvold 2015).

In contrast, columns 5 and 6 report large, statistically significant effects of MMLs on part-time college students' time use. The point estimates suggest that on an average day, after the passage of MMLs, part-time college students spend about 42 fewer minutes on homework and 37 fewer minutes attending class. These estimates are strongly statistically significant and represent increases of more than $100 \%$ relative to the average time spent in these activities prior to the passage of MMLs. Interestingly, these decreases in time spent in educationally productive activities are almost entirely offset by statistically significant increases in time spent 
watching television. ${ }^{8}$ These estimates are robust to the inclusion of a rich set of student-level socio-demographic control variables.

The differences between full-time and part-time college students documented in table 3 are intuitive. Marijuana usage rates, especially heavy use rates, are lower among full-time college students than among their similarly aged peers. For example, the Monitoring the Future survey shows that in 2014, among people who were one to four years beyond high school, the rate of daily marijuana use was about twice as high for non-college goers (10.8\%) as for fulltime college students (5.9\%) (Johnston et al. 2015). Compared to full-time college students, part-time college students tend to be lower performing and of lower socioeconomic status. Data from the National Center for Education Statistics (NCES) suggests that part-time college students are more likely to be Hispanic, first-generation college goers, and to come from lowincome families (Chen 2007). If marijuana usage indeed has negative effects on educational outcomes that are larger for lower-performing students, as found in Marie and Zölitz (2015), we would expect that the academically weaker, socioeconomically disadvantaged, first generation, and traditionally underrepresented students who are more likely to be part-time college students are more susceptible to the harmful effects of marijuana. This hypothesis is consistent with our finding that MMLs affect time use only among part-time college students. We therefore restrict our attention to part-time college students in all subsequent analyses.

To further investigate whether MMLs disproportionately affect traditionally underrepresented students, we estimate the baseline model separately by student race and ethnicity, as college enrollment, persistence, and completion rates for white students are significantly higher than those for black and Hispanic students (e.g., Kane 2004). ${ }^{9}$ Similarly, we examine whether the effects of MMLs vary by gender, because women now complete college at substantially higher rates than men (Bailey \& Dynarski, 2011), and the rate of daily marijuana use among 19- to 30-year-olds was about twice as high for males (10.8\%) as for females (5.9\%) (Johnston et al. 2015). Indeed, Marie and Zölitz (2015) find that the effects of access to marijuana on academic achievement differ by gender.

Columns 1, 2, and 3 in Table 4 estimate the model separately for white, black, and Hispanic students, respectively. Column 1 shows that the results for white students are quite

\footnotetext{
${ }^{8}$ This is consistent with the hypothesis that television viewing displaces time spent reading (Schmidt \& Anderson 2007). The implicit assumption that television viewing is not an educationally productive activity is based on the fact that entertainment programming constitutes the majority of young adults' television viewing (Schmidt \& Anderson 2007) and most educational programming is aimed at children less than 5 years of age (Huston, Bickham, Lee, \& Wright 2007; Schmidt \& Anderson 2007).

${ }^{9}$ We do not test for heterogeneity by socioeconomic status because household income could be reported for the student's household, and this is particularly likely for older, part-time students.
} 
similar to those for the full sample reported in column 6 of table 3, which is unsurprising given that the full sample is predominantly white. Consistent with our hypothesis that underrepresented groups are disproportionately affected by MMLs, column 2 of table 4 shows that the effects of MMLs on black students' time use are two to three times as large as those on white students' time use. Specifically, on average, black students spent nearly two fewer hours per day on homework after the passage of an MML and this effect is strongly statistically significant. The effects on time in class and television viewing are similarly large and of the expected sign, though less precisely estimated, perhaps due to the significantly smaller sample size $(\mathrm{N}=499) .{ }^{10}$ Somewhat surprisingly, we find no evidence that MMLs affected Hispanic students' time doing homework and attending class, as the point estimates are small and statistically insignificant. The point estimate for television time among Hispanics is large and similar in magnitude to that for black students, but is once again imprecisely estimated. Columns 4 and 5 of table 4 estimate the baseline model separately by gender, and actually find that the effects on time use are more pronounced among male students. This is consistent with observed gender gaps in heavy marijuana use and postsecondary success.

Figure 1 presents graphical evidence of MMLs' effects on the time use of part-time college students. To address the concern that the regression results above could be simply an artificial product of our model specifications, we use residuals that partial out only year fixed effects to create Figure 1, and therefore the data used to generate these graphs are very close to the raw data. These graphs show the averages (weighted by the sampling weights) of daily minutes doing homework, attending class, and watching television, before and after MMLs became effective, with 1 on the $\mathrm{X}$-axis denoting the first full year of the law being effective and 0 indicating the first partial year of the law being effective. To be consistent with our regression analysis, only medical marijuana states that passed laws after 2003 are included in the "treatment" group; states that do not have laws or passed laws before 2003 are in the "control" group. To create a comparable control group, we randomly select a proportion of individuals in the control group from each calendar year such that, for each "treatment year" (year relative to passing laws, the $\mathrm{X}$-axis), the control group has a similar proportion of calendar years as in the treatment group. For example, in the treatment group, in year 1, about $4 \%$ of observations are from $2006,10 \%$ are from 2007 , and so on. To obtain a similar

\footnotetext{
${ }^{10}$ Interestingly, although not reported in the paper, we find similarly sized effects of MMLs on homework and television time among black full-time college students.
} 
composition of calendar years, we randomly select $4 \%$ of individuals from the control states in $2006,10 \%$ in 2007 , and so on. ${ }^{11}$

In Figure 1, the series in the control group are approximately flat in all three graphs, suggesting no change in time use after the passage of MMLs. In the upper graph, prior to the implementation of effective MMLs, homework time in the treatment group fluctuates but is roughly centered on zero, and then it trends downward after the implementation of effective MMLs. While these patterns are noisy, notice that the immediate decrease in homework time from year -1 to year 1 (the first full year with effective laws) is 38 minutes, which is close to the estimated effects in Table 3. Moreover, the treatment effects exhibit some dynamics and appear to be decreasing over time. In the middle graph, the in-class time in the treatment group is quite stable (except for year -3) before the implementation of MMLs, then immediately decreases by 34 minutes from year -1 to year 1 after the passage of MMLs. This also closely mirrors the point estimates in Table 3 . These treatment effects seem to be relatively constant over time. In the lower graph, television time for the treatment group seems to increase but is quite noisy. This is consistent with the estimated standard errors for television time in Table 3 being much larger than those for homework time and in-class time. Together, the three panels of Figure 1 provide further evidence that the main results are not spurious and are indeed identified by observable variation in the raw data.

As Figure 1 suggests potential dynamic responses of time use, we replace the dummy variable for MMLs in equation (1) by a series of dummies indicating each year (and a dummy for year 5 and above) after legalization to estimate the dynamic effects of MMLs on student time use. To test for policy endogeneity, that is, whether there were pre-existing trends in the states that eventually implemented MMLs, we also estimate specifications with dummies indicating years prior to legalization. These event-study estimates are presented in Table 5 . We find that the estimates in Table 5 are indeed consistent with Figure 1 and the main estimates reported in Table 3. In column 1 of Table 5, the estimated effects of MMLs (in absolute values) on time spent on doing homework are increasing over time. We find no evidence of policy endogeneity, and the estimates for Year -1 to -2 in column 2 are small and insignificant. The estimates for post-law dummies display the same patterns and magnitudes observed in Figure 1 and Table 3, although they are less precisely estimated. For in-class time in column 3 of

\footnotetext{
${ }^{11}$ Because the control group is not a balanced panel in which the number of observations (respondents) changes over time, we cannot create a composition of calendar years that is exactly the same as the treatment group. Empirically, the composition of calendar years in the control group is indeed very close to that in the treatment group.
} 
Table 5, the estimates for Year 0 to 5+ are quite similar, and they are not statistically significantly different from each other. So the effects of MMLs on in-class time appear to be constant after the passage of an MML. In column 4, the estimates for Year -1 and Year -2 are positive and therefore it is not a concern that in-class time decreases prior to the passage of MMLs. The estimated magnitudes for Year -1 and Year -2 are quite large, however, which leads the estimates for post-law dummies to become small and insignificant. As seen from Figure 1, this anomaly is due to in-class time in Year -3 being quite low, which is probably a sampling issue. ${ }^{12}$ The estimates in columns 5 and 6 suggest positive effects of MMLs, but they are quite noisy and lack a consistent pattern. Nevertheless, these estimates remain consistent with Figure 1. For example, the effects on television time are greatest in Year 1 and smallest in Year 2. Overall, except for homework time, we find little evidence of dynamic responses of time use to MMLs. Given the relatively small number of observations in our part-time college student sample, these estimates for dynamic effects are a bit noisy, and a single post-treatment dummy that averages MMLs' effects is a reasonable approximation of the true policy effects. ${ }^{13}$

In Table 6, we estimate the effects of MMLs on time use using different definitions of time use. A large proportion of part-time college students in the survey report zero time in homework $(73 \%)$, in-class $(83 \%)$, and television $(29 \%) .{ }^{14}$ One natural question is whether changes in time use are due to changes at the extensive margin or the intensive margin. To address this question, we create dummy variables indicating any time spent in each activity, and then estimate the effects of MMLs on the likelihoods of whether a college part-time student participated in the activity on the diary day. If there is no effect of MMLs on participation, then the results presented in Table 3 suggest that MMLs change people's time use mainly at the intensive margin; otherwise, the extensive margin plays an important role. These results are reported in the upper panel of Table 6. We find that the extensive margin is an important channel for explaining changes in homework and class time. In columns 1 and 2, MMLs decrease the likelihood of doing homework by 21 percentage points and the likelihood of attending class by 16 percentage points. However, in column 3, the estimate is very small and

\footnotetext{
${ }^{12}$ There are 42 observations of Year -3 in the treatment group in Figure 1, and 40 of them report zero in-class time. If we drop these 42 observations, the pre-law estimates in Column (4) are close to zero while the post-law estimates in Column (4) are quantitatively similar to those in Column (3) and highly significant.

${ }^{13} \mathrm{We}$ also estimate the dynamic effects of MMLs for high school students and college full-time students. The results are consistent with the estimates in Table 3 and do not show any significant effect of MMLs on time use.

${ }^{14}$ One might be worried about that linear models provide a poor fit for the data. We also estimate the effects of MMLs by fixed effects Poisson models, and the results are quantitatively similar. These results are available upon request.
} 
insignificant, so the increase in television time shown in previous tables is primarily driven by behavioral changes on the intensive margin.

Since the ATUS asks respondents how much they sleep, we can also measure time spent on homework, attending class, and watching television as proportions of non-sleep time. In the lower panel, we see that these results are qualitatively similar to estimates of the baseline models, measured in daily minutes, reported in Table 3 . The estimates in columns 1 and 2 show that, in terms of the percentage of non-sleep time, part-time-college students spend 5\% less non-sleep time on doing homework and $4 \%$ less non-sleep time attending class after the passage of MMLs. In column 3, the estimate for television time is large and suggests that parttime-college students spend 5\% more non-sleep time on watching television, though this estimate is not statistically significant at traditional confidence levels.

In Table 7, we further check the robustness of our results. The survey is at the individual level, while MMLs vary only at the state level. Roughly, the MML estimates from individuallevel regressions are the weighted average of the policy effects in each state weighted by state populations. One concern is that the difference-in-difference estimates could be driven by one or two states with larger populations in the presence of heterogeneous treatment effects (Solon, Haider, and Wooldridge 2015). To address this, we average the individual-level data to the state-level, including the dependent variables for time use and all of the control variables, and re-run the regressions at the state-level. The estimates are shown in column 1. As expected, the estimated standard errors become larger: the estimates for homework time and television time remain significant at the $10 \%$ level, while the estimate for in-class time loses its significance. Nevertheless, the point estimates are qualitatively similar to those in Table 3 . This suggests that the baseline estimates of the effects of MMLs are not driven by larger states.

Finally, we test whether our results are sensitive to different sample restrictions. In column 2, we restrict our sample to diaries that were recorded during the academic year from September to May. Except for the estimate for homework time, the estimates for in-class time and television time become slightly larger and more precise than those in Table 3 . In column 3, we exclude states that passed MMLs prior to 2003 from the sample. Because our data are available since 2003 , these medical marijuana states do not directly contribute to identifying the estimates of MMLs. One may be concerned with treating these medical marijuana states as control groups. The estimates in column 3 remain qualitatively similar to the baseline estimates reported in Table 3 and continue to show negative impacts of MMLs on homework time and in-class time and positive impacts on television time. In sum, the results presented in Tables 6 
and 7 show that the main finding of significant, arguably causal effects of MMLs on part-time college students' time use are robust to a variety of modeling choices.

\section{Conclusion}

The current study uses a difference-in-differences strategy to estimate the effect of medical marijuana laws (MMLs) on students' time use. We find robust, arguably causal evidence that the passage of MMLs affected part-time postsecondary students' time use, but not that of secondary or full-time postsecondary students. Specifically, part-time postsecondary students spent about 42 fewer minutes per day on homework, 37 fewer minutes per day attending class, and about one more hour per day watching television than their parttime postsecondary counterparts in non-MML states. These effects are larger among male and black students and are approximately constant over time.

These results provide indirect evidence that marijuana use induced by increased access to marijuana affects relatively disadvantaged students' educational outcomes. They also provide evidence on the mechanisms through which marijuana use likely affects academic achievement. Still, a caveat of the current study is that we lack data on individual students' drug use, so these estimates are best interpreted as the reduced-form impact of policies that affect access to marijuana on student behaviors. Similarly, the ATUS data do not contain direct measures of academic achievement or persistence in postsecondary education, due to the crosssectional nature of the survey. Still, these results identify a potentially important, and costly, unintended consequence of MML that might perpetuate socioeconomic inequities by delaying, or limiting, the postsecondary educational success of students from certain socio-demographic backgrounds. 


\section{References}

Anderson, D., Mark, Benjamin Hansen, \& Daniel I. Rees. 2013. Medical marijuana laws, traffic fatalities, and alcohol consumption. Journal of Law and Economics 56(2): 333369.

Anderson, D. Mark, Daniel I. Rees, \& Joseph J. Sabia. 2014. Medical marijuana laws and suicides by gender and age. American Journal of Public Health 104(12): 2369-2376.

Anderson, Mark D., Benjamin Hansen, \& Daniel I. Rees. 2015. Medical marijuana laws and teen marijuana use. American Law and Economics Review 17(2): 495-528.

Bailey, M. J., \& Dynarski, S. M. 2011. Gains and gaps: Changing inequality in US college entry and completion No. w17633. Cambridge, MA: National Bureau of Economic Research.

Batalla, A., J. A. Crippa, G. F. Busatto, F. S. Guimaraes, A. W. Zuardi, O. Valverde, Z. Atakan, P. K. McGuire, S. Bhattacharyya, \& R. Martín-Santos. 2014. Neuroimaging studies of acute effects of thc and cbd in humans and animals: a systematic review. Current Pharmaceutical Design 20(13): 2168-2185.

Bergen, Sarah E., Charles O. Gardner, Steven H. Aggen, \& Kenneth S. Kendler. 2008. Socioeconomic status and social support following illicit drug use: causal pathways or common liability? Twin research and human genetics: the official journal of the International Society for Twin Studies 11(3): 266-274.

Bolla, Karen I., Dana A. Eldreth, John A. Matochik, \& Jean L. Cadet. 2005. Neural substrates of faulty decision-making in abstinent marijuana users. NeuroImage 26(2): 480-492.

Bray, Jeremy W., Gary A. Zarkin, Chris Ringwalt, \& Junfeng Qi. 2000. The relationship between marijuana initiation and dropping out of high school. Health Economics 9(1): 9-18.

Cerdá, Magdalena, Melanie Wall, Katherine M. Keyes, Sandro Galea, \& Deborah Hasin. 2012. Medical marijuana laws in 50 states: Investigating the relationship between state legalization of medical marijuana and marijuana use, abuse and dependence. Drug and Alcohol Dependence 120(1-3): 22-27.

Chatterji, Pinka. 2006. Illicit drug use and educational attainment. Health Economics 15(5): 489-511.

Chen, Xianglei. 2007. Part-time undergraduates in postsecondary education: 2003-04 (NCES 2007-165). U.S. Department of Education. Washington, DC: National Center for Education Statistics.

Chu, Yu-Wei Luke. 2014. The effects of medical marijuana laws on illegal marijuana use. Journal of Health Economics 38: 43-61.

- 2015. Do medical marijuana laws increase hard drug use? The Journal of Law and Economics 58(2): 481-517.

Conley, Timothy G, \& Christopher R Taber. 2011. Inference with "difference in differences" with a small number of policy changes. The Review of Economics and Statistics 93(1): 113-125.

Degenhardt, Louisa, Wayne Hall, \& Michael Lynskey. 2003. Exploring the association between cannabis use and depression. Addiction 98(11): 1493-1504.

Denson, Thomas F., \& Mitchell Earleywine. 2006. Decreased depression in marijuana users. Addictive Behaviors 31(4): 738-742.

Duarte, Rosa, José-Julián Escario, \& José-Alberto Molina. 2009. 'Me, my classmates and my buddies': analysing peer group effects on student marijuana consumption. Education Economics 19(1): 89-105. 
Duarte, Rosa, José Julián Escario, \& José Alberto Molina. 2006. Marijuana consumption and school failure among Spanish students. Economics of Education Review 25(5): 472481.

Eddy, Mark. 2010. Medical marijuana: review and analysis of federal and state policies. Congressional Research Service no. RL33211.

Filbey, Francesca M., Sina Aslan, Vince D. Calhoun, Jeffrey S. Spence, Eswar Damaraju, Arvind Caprihan, \& Judith Segall. 2014. Long-term effects of marijuana use on the brain. Proceedings of the National Academy of Sciences 111(47): 16913-16918.

Foltin, Richard W., Marian W. Fischman, Joseph V. Brady, Thomas H. Kelly, Daniel J. Bernstein, \& Margaret J. Nellis. 1989. Motivational effects of smoked marijuana: Behavioral contingencies and high-probability recreational activities. Pharmacology Biochemistry and Behavior 34(4): 871-877.

GAO, General Accounting Office. 2002. Marijuana: early experiences with four states' laws that allow use for medical purposes. Washington, DC.

Gaviria, Alejandro, \& Steven Raphael. 2001. School-based peer effects and juvenile behavior. Review of Economics and Statistics 83(2): 257-268.

Gilman, Jodi M., John K. Kuster, Sang Lee, Myung Joo Lee, Byoung Woo Kim, Nikos Makris, Andre van der Kouwe, Anne J. Blood, \& Hans C. Breiter. 2014. Cannabis use is quantitatively associated with nucleus accumbens and amygdala abnormalities in young adult recreational users. The Journal of Neuroscience 34(16): 5529-5538.

Grant, Julia D., Jeffrey F. Scherrer, Michael T. Lynskey, Arpana Agrawal, Alexis E. Duncan, Jon Randolph Haber, Andrew C. Heath, \& Kathleen K. Bucholz. 2012. Associations of alcohol, nicotine, cannabis and drug use/dependence with educational attainment: evidence from Cotwin-control analyses. Alcoholism, clinical and experimental research 36(8): 1412-1420.

Griffith-Lendering, Merel F. H., Stephan C. J. Huijbregts, Wilma A. M. Vollebergh, \& Hanna Swaab. 2012. Motivational and cognitive inhibitory control in recreational cannabis users. Journal of Clinical and Experimental Neuropsychology 34(7): 688697.

Grimm, P. 2010. Social desirability bias. New York, NY: Wiley International.

Jacob, B. A. 2002. Where the boys aren't: non-cognitive skills, returns to school, and the gender gap in higher education. Economics of Education Review 21(6): 589-598.

Johnston, Lloyd D., Patrick M. O' Malley, Jerald G. Bachman, John E. Schulenberg, \& Richard A. Miech. 2015. Monitoring the future national survey results on drug use, 1975-2014: Volume 2, College students and adults ages 19-55.

Juster, F. T., \& Stafford, F. P. 1991. The allocation of time: empirical findings, behavioral models, and problems of measurement. Journal of Economic Literature, 29(2): 471522.

Kalenkoski, C. M., \& Pabilonia, S. W. 2014. Does high school homework increase academic achievement? IZA Discussion Paper No. 8142. Bonn: IZA.

Kane, T. J. 2004. College-going and inequality. In K. M. Neckerman (Ed.), Social Inequality (pp. 319-354). New York: Russell Sage Foundation.

Khatapoush, Shereen, \& Denise Hallfors. 2004. "Sending the wrong message": did medical marijuana legalization in California change attitudes about and use of marijuana? Journal of Drug Issues 34(4): 751-770.

Lane, Scott D., Don R. Cherek, Cynthia J. Pietras, \& Joel L. Steinberg. 2005. Performance of heavy marijuana-smoking adolescents on a laboratory measure of motivation. Addictive Behaviors 30(4): 815-828.

Lynskey, Michael, \& Wayne Hall. 2000. The effects of adolescent cannabis use on educational attainment: a review. Addiction 95(11): 1621-1630. 
Macleod, John, Rachel Oakes, Alex Copello, Ilana Crome, Matthias Egger, Mathew Hickman, Thomas Oppenkowski, Helen Stokes-Lampard, \& George Davey Smith. 2004. Psychological and social sequelae of cannabis and other illicit drug use by young people: a systematic review of longitudinal, general population studies. The Lancet 363(9421): 1568-1569.

Marie, Olivier, \& Ulf Zölitz. 2015. 'High' achievers? Cannabis access and academic performance. IZA Discussion Paper No. 8900.

McCaffrey, Daniel F., Rosalie Liccardo Pacula, Bing Han, \& Phyllis Ellickson. 2010. Marijuana use and high school dropout: the influence of unobservables. Health Economics 19(11): 1281-1299.

Mikos, Robert A. 2011. A critical appraisal of the Department of Justice's new approach to medical marijuana. Stanford Law \& Policy Review 22(2): 633-670.

Musty, Richard E., \& Lee Kaback. 1995. Relationships between motivation and depression in chronic marijuana users. Life Sciences 56(23-24): 2151-2158.

Pacula, Rosalie L., Anne E. Boustead, and Priscillia Hunt. 2014. Words can be deceiving: a review of variation among legally effective medical marijuana laws in the United States. Journal of Drug Policy Analysis 7(1): 1-19.

Pacula, Rosalie L., David Powell, Paul Heaton, \& Eric L. Sevigny. 2015. Assessing the effects of medical marijuana laws on marijuana use: the devil is in the details. Journal of Policy Analysis and Management 34(1): 7-31.

Pacula, Rosalie Liccardo, Jamie F. Chriqui, Deborah A. Reichmann, \& Yvonne M. TerryMcElrath. 2002. State medical marijuana laws: understanding the laws and their limitations. Journal of Public Health Policy 23(4): 413-439.

Powell, David, Rosalie Liccardo Pacula, \& Mireille Jacobs. 2015. Do medical marijuana laws reduce addiction and deaths related to pain killers? RAND Corporation, WR-1130, http://www.rand.org/pubs/working_papers/WR1130.html.

Price, Jenessa S., Tim McQueeny, Skyler Shollenbarger, ErinL Browning, Jon Wieser, \& KristaM Lisdahl. 2015. Effects of marijuana use on prefrontal and parietal volumes and cognition in emerging adults. Psychopharmacology 232(16): 2939-2950.

ProCon.org. 2016. Number of legal medical marijuana patients. Retrieved April 2, 2016, from http://medicalmarijuana.procon.org/view.resource.php?resourceID=005889.

Randolph, Kristen, Paris Turull, Amy Margolis, \& Gregory Tau. 2013. Cannabis and cognitive systems in adolescents. Adolescent Psychiatry 3(2): 135-147.

Raver, Sylvina M., Sarah P. Haughwout, \& Asaf Keller. 2013. Adolescent cannabinoid exposure permanently suppresses cortical oscillations in adult mice. Neuropsychopharmacology 38(12): 2338-2347.

Roebuck, M. Christopher, Michael T. French, \& Michael L. Dennis. 2004. Adolescent marijuana use and school attendance. Economics of Education Review 23(2): 133-141.

Salomonsen-Sautel, Stacy, Joseph T. Sakai, Christian Thurstone, Robin Corley, \& Christian Hopfer. 2012. Medical marijuana use among adolescents in substance abuse treatment. Journal of the American Academy of Child and Adolescent Psychiatry 51(7): 694-702.

Sabia, J. J., Swigert, J., \& Young, T. 2015. The effect of medical marijuana laws on body weight. In Press, Health Economics. DOI: 10.1002/hec.3267

Sander, William. 1998. The effects of schooling and cognitive ability on smoking and marijuana use by young adults. Economics of Education Review 17(3): 317-324.

Shannon, Erin E., Charles W. Mathias, Donald M. Dougherty, \& Anthony Liguori. 2010. Cognitive impairments in adolescent cannabis users are related to THC levels. Addictive Disorders \& Their Treatment 9(4): 158-163. 
Solon, Gary, Steven J. Haider, \& Jeffrey M. Wooldridge. 2015. What are we weighting for? Journal of Human Resources 50(2): 301-316.

Stewart, J. 2013. Tobit or not Tobit? Journal of Economic and Social Measurement, 38(3): 263-290.

Thurstone, Christian, Shane A. Lieberman, \& Sarah J. Schmiege. 2011. Medical marijuana diversion and associated problems in adolescent substance treatment. Drug and Alcohol Dependence 118(2-3): 489-492.

Vaidya, Jatin G., Robert I. Block, Daniel S. O'Leary, Laura B. Ponto, Mohamed M. Ghoneim, \& Antoine Bechara. 2012. Effects of chronic marijuana use on brain activity during monetary decision-making. Neuropsychopharmacology 37(3): 618629.

van Ours, Jan C., \& Jenny Williams. 2009. Why parents worry: initiation into cannabis use by youth and their educational attainment. Journal of Health Economics 28(1): 132142.

Verdejo-Garcia, Antonio, Amy Benbrook, Frank Funderburk, Paula David, Jean-Lud Cadet, \& Karen I. Bolla. 2007. The differential relationship between cocaine use and marijuana use on decision-making performance over repeat testing with the Iowa Gambling Task. Drug and Alcohol Dependence 90(1): 2-11.

Verweij, Karin J. H., Anja C. Huizink, Arpana Agrawal, Nicholas G. Martin, \& Michael T. Lynskey. 2013. Is the relationship between early-onset cannabis use and educational attainment causal or due to common liability? Drug and alcohol dependence 133(2): 580-586.

Wall, Melanie M., Ernest Poh, Magdalena Cerdá, Katherine M. Keyes, Sandro Galea, \& Deborah S. Hasin. 2011. Adolescent marijuana use from 2002 to 2008: higher in states with medical marijuana laws, cause still unclear. Annals of epidemiology 21(9): 714-716.

Weiland, B. J., R. E. Thayer, B. E. Depue, A. Sabbineni, A. D. Bryan, \& K. E. Hutchison. 2015. Daily marijuana use is not associated with brain morphometric measures in adolescents or adults. J Neurosci 35(4): 1505-12.

Wen, Hefei, Jason M. Hockenberry, \& Janet R. Cummings. 2015. The effect of medical marijuana laws on adolescent and adult use of marijuana, alcohol, and other substances. Journal of Health Economics 42: 64-80.

Wesley, Michael J., Colleen A. Hanlon, \& Linda J. Porrino. 2011. Poor decision-making by chronic marijuana users is associated with decreased functional responsiveness to negative consequences. Psychiatry Research: Neuroimaging 191(1): 51-59.

Wetherell, Mark A., Katie Atherton, Jessica Grainger, Robert Brosnan, \& Andrew B. Scholey. 2012. The effects of multitasking on psychological stress reactivity in recreational users of cannabis and MDMA. Human Psychopharmacology: Clinical and Experimental 27(2): 167-176.

Whitlow, Christopher T., Anthony Liguori, L. Brooke Livengood, Stephanie L. Hart, Becky J. Mussat-Whitlow, Corey M. Lamborn, Paul J. Laurienti, \& Linda J. Porrino. 2004. Long-term heavy marijuana users make costly decisions on a gambling task. Drug and Alcohol Dependence 76(1): 107-111.

Wooldridge, J. M. 2010. Econometric analysis of cross section and panel data, 2nd ed. Cambridge, MA: MIT Press.

Yamada, Tetsuji, Michael Kendix, \& Tadashi Yamada. 1996. The impact of alcohol consumption and marijuana use on high school graduation. Health Economics 5(1): 77-92. 
Zimmerman, Marc A., \& Karen H. Schmeelk-Cone. 2003. A longitudinal analysis of adolescent substance use and school motivation among African American youth. Journal of Research on Adolescence 13(2): 185-210. 

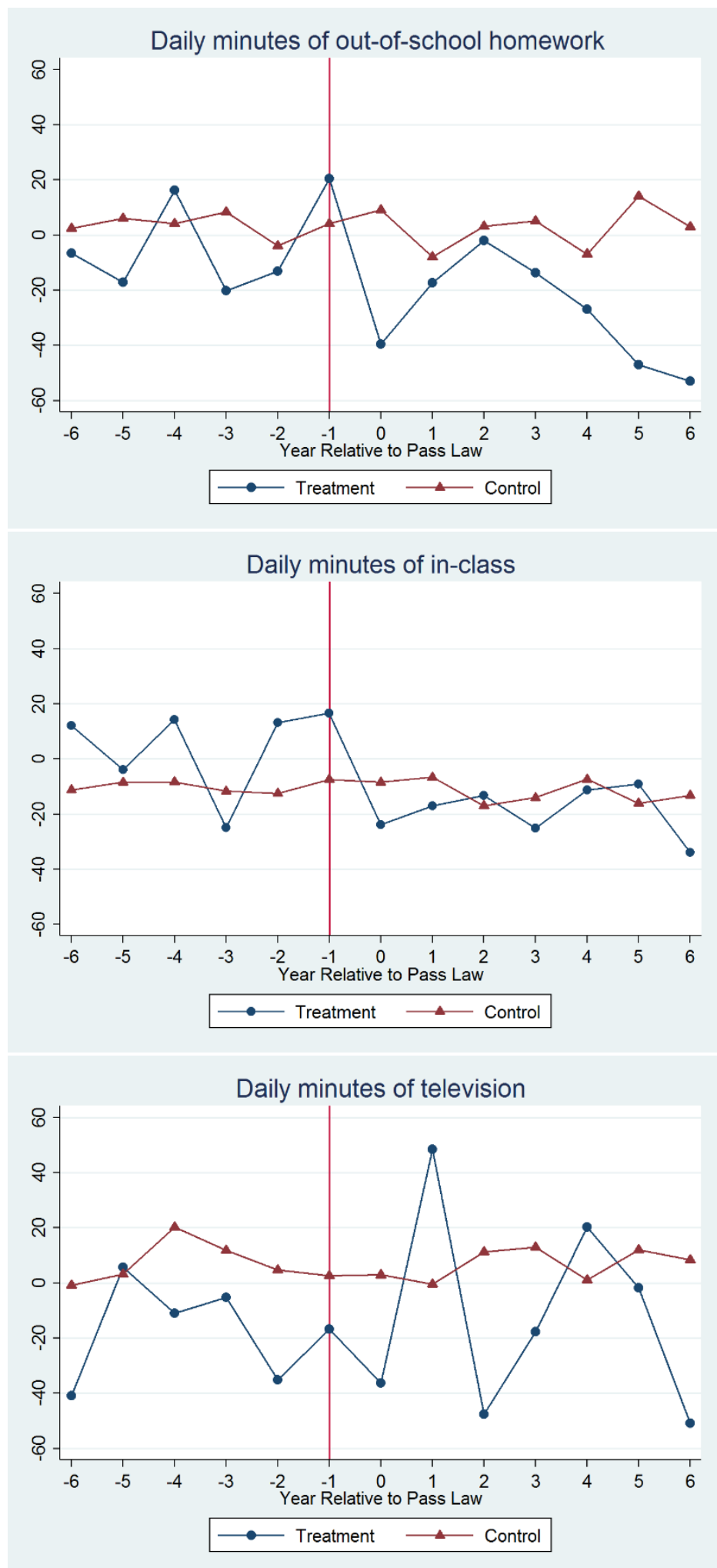

Figure 1: Time Use before and after MMLs 
Table 1: State Medical Marijuana Laws as of July 2015

\begin{tabular}{|c|c|c|c|}
\hline State & Date Effective & State & Date Effective \\
\hline Alaska & $03 / 04 / 1999$ & Michigan & $12 / 04 / 2008$ \\
\hline Arizona & $04 / 14 / 2011$ & Minnesota & $05 / 30 / 2014$ \\
\hline California & $11 / 06 / 1996$ & Montana & $11 / 02 / 2004$ \\
\hline Colorado & $06 / 01 / 2001$ & Nevada & $10 / 01 / 2001$ \\
\hline Connecticut & $05 / 31 / 2012$ & New Hampshire & $07 / 23 / 2013$ \\
\hline D.C & $07 / 27 / 2010$ & New Jersey & $01 / 18 / 2010$ \\
\hline Delaware & $07 / 01 / 2011$ & New Mexico & $07 / 01 / 2007$ \\
\hline Hawaii & $12 / 28 / 2000$ & New York & $07 / 05 / 2014$ \\
\hline Illinois & $01 / 01 / 2014$ & Oregon & $12 / 03 / 1998$ \\
\hline Maine & $12 / 22 / 1999$ & Rhode Island & $01 / 03 / 2006$ \\
\hline Maryland & $06 / 01 / 2014$ & Vermont & $07 / 01 / 2004$ \\
\hline Massachusetts & $01 / 01 / 2013$ & Washington & $11 / 03 / 1998$ \\
\hline
\end{tabular}

Notes: Only states that passed laws before 2014 are coded as medical marijuana states in the paper. See ProCon.org (2016) for legal documents and details of laws. 


\begin{tabular}{|c|c|c|c|c|c|c|}
\hline & \multicolumn{2}{|c|}{ High School } & \multicolumn{2}{|c|}{$\begin{array}{c}\text { Full-Time } \\
\text { College }\end{array}$} & \multicolumn{2}{|c|}{$\begin{array}{l}\text { Part-Time } \\
\text { College }\end{array}$} \\
\hline & Mean & SD & Mean & $\mathrm{SD}$ & Mean & SD \\
\hline Homework & 47.8 & 1.3 & 92.4 & 3.1 & 43.4 & 2.3 \\
\hline $\mathrm{HW}$ (if $>0$ ) & 113.4 & 2.3 & 214.2 & 5.2 & 161.0 & 5.4 \\
\hline $\operatorname{Pr}(\mathrm{HW}>0)$ & 0.42 & & 0.43 & & 0.27 & \\
\hline Class & 206.0 & 3.1 & 70.7 & 2.9 & 31.9 & 2.3 \\
\hline Class (if $>0$ ) & 375.9 & 2.1 & 230.3 & 5.6 & 188.4 & 7.0 \\
\hline $\operatorname{Pr}($ Class $>0)$ & 0.55 & & 0.31 & & 0.17 & \\
\hline Television & 124.9 & 2.0 & 116.8 & 2.5 & 108.7 & 2.8 \\
\hline TV (if $>0$ ) & 164.2 & 2.2 & 165.7 & 2.9 & 153.0 & 3.3 \\
\hline $\operatorname{Pr}(\mathrm{TV}>0)$ & 0.76 & & 0.70 & & 0.71 & \\
\hline Male & 0.51 & & 0.45 & & 0.41 & \\
\hline Age & 16.32 & 0.016 & 24.14 & 0.11 & 30.47 & 0.21 \\
\hline $\begin{array}{l}\text { Metro } \\
\text { Locale }\end{array}$ & 0.84 & & 0.87 & & 0.89 & \\
\hline White & 0.78 & & 0.77 & & 0.80 & \\
\hline Black & 0.15 & & 0.14 & & 0.13 & \\
\hline Hispanic & 0.22 & & 0.13 & & 0.18 & \\
\hline Asian & 0.04 & & 0.07 & & 0.04 & \\
\hline $\mathrm{N}$ & & & & & & \\
\hline
\end{tabular}


Table 3: Baseline Estimates of MMLs' Impact on Students' Daily Time Use

\begin{tabular}{|c|c|c|c|c|c|c|}
\hline & \multicolumn{2}{|c|}{ High School } & \multicolumn{2}{|c|}{$\begin{array}{c}\text { Full-Time } \\
\text { College }\end{array}$} & \multicolumn{2}{|c|}{ Part-Time College } \\
\hline & (1) & (2) & (3) & (4) & $(5)$ & (6) \\
\hline Homework & $\begin{array}{c}11.1 \\
(15.3)\end{array}$ & $\begin{array}{c}13.6 \\
(13.5)\end{array}$ & $\begin{array}{c}35.9 \\
(37.3)\end{array}$ & $\begin{array}{c}32.8 \\
(37.0)\end{array}$ & $\begin{array}{c}-42.6 \\
(11.8)^{* * *}\end{array}$ & $\begin{array}{c}-41.7 \\
(12.8)^{* * *}\end{array}$ \\
\hline Adj. $R^{2}$ & 0.08 & 0.13 & 0.08 & 0.10 & 0.05 & 0.05 \\
\hline Pre-law Avg. & \multicolumn{2}{|c|}{49.1} & \multicolumn{2}{|c|}{82.2} & \multicolumn{2}{|c|}{41.3} \\
\hline Class & $\begin{array}{c}5.5 \\
(11.5)\end{array}$ & $\begin{array}{c}1.9 \\
(12.4)\end{array}$ & $\begin{array}{c}16.4 \\
(17.6)\end{array}$ & $\begin{array}{l}13.1 \\
(16.6)\end{array}$ & $\begin{array}{c}-37.3 \\
(15.9)^{* *} \\
0.08\end{array}$ & $\begin{array}{c}-36.5 \\
(16.7)^{* *} \\
0.09\end{array}$ \\
\hline Pre-law Avg. & \multicolumn{2}{|c|}{131.1} & \multicolumn{2}{|c|}{49.3} & \multicolumn{2}{|c|}{22.5} \\
\hline Television & $\begin{array}{c}-18.2 \\
(11.0) \\
0.04\end{array}$ & $\begin{array}{c}-22.0 \\
(11.2)^{*} \\
0.05\end{array}$ & $\begin{array}{c}-28.2 \\
(24.6) \\
0.05\end{array}$ & $\begin{array}{c}-23.6 \\
(23.1) \\
0.07\end{array}$ & $\begin{array}{c}63.7 \\
(29.8)^{* *} \\
0.06\end{array}$ & $\begin{array}{c}60.4 \\
(31.8)^{*} \\
0.07\end{array}$ \\
\hline Pre-law Avg. & \multicolumn{2}{|c|}{137.1} & \multicolumn{2}{|c|}{115.4} & \multicolumn{2}{|c|}{108.3} \\
\hline $\mathrm{N}$ & \multicolumn{2}{|c|}{6,313} & \multicolumn{2}{|c|}{5,090} & \multicolumn{2}{|c|}{3,276} \\
\hline $\begin{array}{l}\text { Student } \\
\text { Controls }\end{array}$ & No & Yes & No & Yes & No & Yes \\
\hline
\end{tabular}

Notes: Time use is measured in daily minutes. Each cell reports the coefficient estimate on the MML indicator from a unique regression. All models contain state, year, diary month, and diary day fixed effects, state-specific linear time trends, and indicators for marijuana decriminalization and marijuana legalization. All estimates are weighted by person-day weights that adjust for the unequal probability of sample selection across both households and days. Standard errors are robust to clustering by state.

$* * * \mathrm{p}<0.01 . * * \mathrm{p}<0.05 . * \mathrm{p}<0.10$. 
Table 4: Estimates of MMLs' Impact on Part-Time College Students' Daily Time Use, by Gender and Races

\begin{tabular}{|c|c|c|c|c|c|}
\hline & $\begin{array}{l}\text { White } \\
\text { (1) }\end{array}$ & $\begin{array}{c}\text { Black } \\
\text { (2) }\end{array}$ & $\begin{array}{c}\text { Hispanic } \\
\text { (3) }\end{array}$ & $\begin{array}{l}\text { Male } \\
\text { (4) }\end{array}$ & $\begin{array}{c}\text { Female } \\
\text { (5) }\end{array}$ \\
\hline Homework & $\begin{array}{c}-42.7 \\
(16.4)^{* *}\end{array}$ & $\begin{array}{c}-107.5 \\
(35.1)^{* * *}\end{array}$ & $\begin{array}{c}21.1 \\
(38.0)\end{array}$ & $\begin{array}{l}-54.6 \\
(55.3)\end{array}$ & $\begin{array}{l}-20.9 \\
(26.3)\end{array}$ \\
\hline $\begin{array}{l}\text { Pre-law } \\
\text { Avg. }\end{array}$ & 33.2 & 38.6 & 30.5 & 27.8 & 43.8 \\
\hline Class & $\begin{array}{c}-41.2 \\
(21.9)^{*}\end{array}$ & $\begin{array}{r}-134.4 \\
(85.1)\end{array}$ & $\begin{array}{c}9.8 \\
(46.8)\end{array}$ & $\begin{array}{l}-28.9 \\
(34.1)\end{array}$ & $\begin{array}{l}-22.3 \\
(22.7)\end{array}$ \\
\hline $\begin{array}{l}\text { Pre-law } \\
\text { Avg. }\end{array}$ & 32.7 & 41.1 & 51.9 & 36.9 & 35.1 \\
\hline Television & $\begin{array}{c}64.6 \\
(24.8)^{* *}\end{array}$ & $\begin{array}{c}132.3 \\
(151.1)\end{array}$ & $\begin{array}{l}138.8 \\
(93.9)\end{array}$ & $\begin{array}{c}93.4 \\
(38.6)^{* *}\end{array}$ & $\begin{array}{c}56.4 \\
(48.3)\end{array}$ \\
\hline $\begin{array}{l}\text { Pre-law } \\
\text { Avg. }\end{array}$ & 92.5 & 115.4 & 106.5 & 95.1 & 96.8 \\
\hline $\mathrm{N}$ & 2,559 & 499 & 506 & 1,116 & 2,160 \\
\hline $\begin{array}{l}\text { Student } \\
\text { controls }\end{array}$ & Yes & Yes & Yes & Yes & Yes \\
\hline
\end{tabular}

Notes: Time use is measured in daily minutes. Each cell reports the coefficient estimate on the MML indicator from a unique regression. All models contain state, year, diary month, and diary day fixed effects, state-specific linear time trends, and indicators for marijuana decriminalization and marijuana legalization. All estimates are weighted by person-day weights that adjust for the unequal probability of sample selection across both households and days. Standard errors are robust to clustering by state. $* * * p<0.01 . * * \mathrm{p}<0.05 . * \mathrm{p}<0.10$. 
Table 5: Estimates of Dynamic Effects of MML on Part-Time College Students' Daily

Time Use

Homework

Class

Television

(1)

(2)

(3)

(4)

(5)

(6)

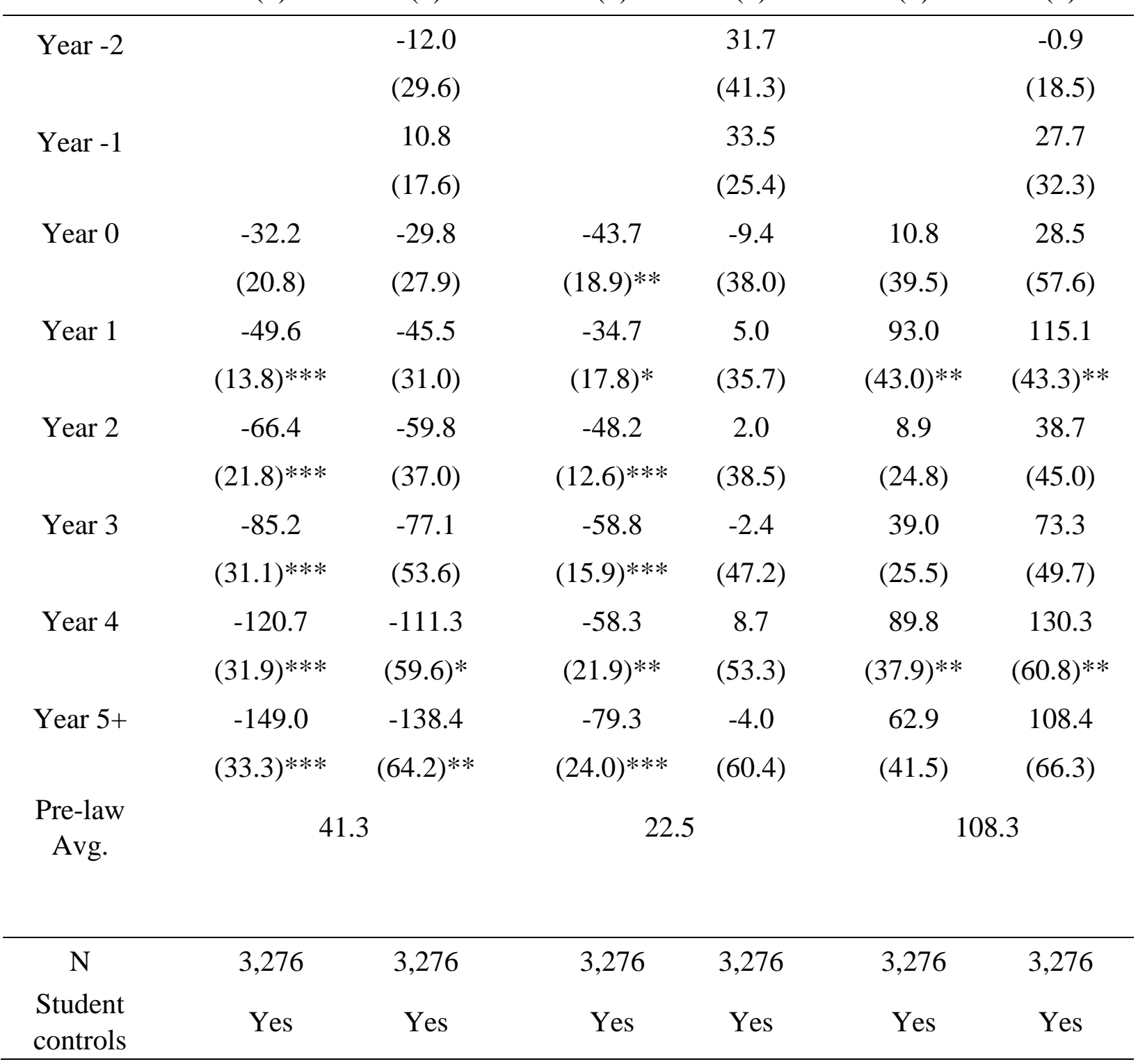

Notes: All models contain state, year, diary month, and diary day fixed effects, state-specific linear time trends, and indicators for marijuana decriminalization and marijuana legalization. All estimates are weighted by person-day weights that adjust for the unequal probability of sample selection across both households and days. Standard errors are robust to clustering by state. $* * * \mathrm{p}<0.01 . * * \mathrm{p}<0.05 . * \mathrm{p}<0.10$. 
Table 6: Estimates of MMLs' Impact on Part-Time College Students' Daily Time Use, Alternative Measures

\begin{tabular}{lccc}
\hline & Homework & Class & Television \\
& $(1)$ & $(2)$ & $(3)$ \\
\hline Extensive margin & -0.21 & -0.16 & -0.01 \\
Pre-law Avg. & $(0.09)^{* *}$ & $(0.09)^{*}$ & $(0.14)$ \\
& 0.30 & 0.20 & 0.76 \\
Proportion of & & & \\
non-sleep time & -0.05 & -0.04 & 0.05 \\
Pre-law Avg. & $(0.01)^{* * *}$ & $(0.02)^{* *}$ & $(0.04)$ \\
& 0.04 & 0.04 & 0.11 \\
\hline N & & & 3,276 \\
Student controls & 3,276 & 3,276 & Yes \\
\hline
\end{tabular}

Notes: All models contain state, year, diary month, and diary day fixed effects, state-specific linear time trends, and indicators for marijuana decriminalization and marijuana legalization. All estimates are weighted by person-day weights that adjust for the unequal probability of sample selection across both households and days. Standard errors are robust to clustering by state. $* * * \mathrm{p}<0.01$. ** $\mathrm{p}<0.05$. * $\mathrm{p}<0.10$. 
Table 7: Robustness Checks

\begin{tabular}{|c|c|c|c|}
\hline & $\begin{array}{c}\text { State-level } \\
\text { Regression } \\
\text { (1) }\end{array}$ & $\begin{array}{c}\text { Academic Year } \\
\text { (Sep. - May) } \\
\text { (2) }\end{array}$ & $\begin{array}{c}\text { No MJ states } \\
\text { before } 2003 \\
(3)\end{array}$ \\
\hline \multirow{2}{*}{ Homework } & -46.3 & -23.097 & -42.1 \\
\hline & $(26.4)^{*}$ & $(12.152)^{*}$ & $(14.9)^{* * *}$ \\
\hline Pre-law Avg. & 38.2 & 37.2 & 37.4 \\
\hline \multirow{2}{*}{ Class } & -30.8 & -45.448 & -38.1 \\
\hline & $(21.3)$ & $(14.149)^{* * *}$ & $(14.4)^{* *}$ \\
\hline Pre-law Avg. & 32.5 & 39.3 & 35.8 \\
\hline \multirow{2}{*}{ Television } & 72.4 & 75.195 & 64.4 \\
\hline & $(38.9)^{*}$ & $(30.645)^{* *}$ & $(32.0)^{*}$ \\
\hline Pre-law Avg. & 97.8 & 94.0 & 96.1 \\
\hline Obs. & 486 & 2,562 & 2,604 \\
\hline $\begin{array}{l}\text { Student } \\
\text { controls }\end{array}$ & Yes & Yes & Yes \\
\hline
\end{tabular}

Notes: All models contain state, year, diary month, and diary day fixed effects, state-specific linear time trends, and indicators for marijuana decriminalization and marijuana legalization. All estimates are weighted by person-day weights that adjust for the unequal probability of sample selection across both households and days. Standard errors are robust to clustering by state. $* * * \mathrm{p}<0.01 . * * \mathrm{p}<0.05 . * \mathrm{p}<0.10$. 